\title{
Gesamtverzeichnis des
}

\section{deutschsprachigen Schriftums (GV)}

$$
1700-1910
$$

Bearbeitet unter der Leitung von

Hilmar Schmuck und Willi Gorzny

Bibliographische und redaktionelle Beratung:

Hans Popst und Rainer Schöller

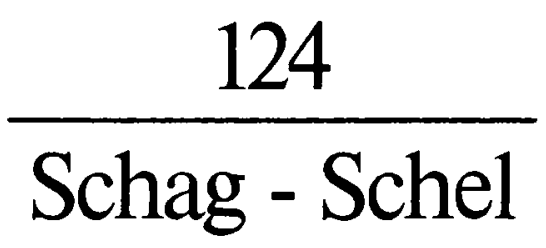


Gesamtverzeichnis des deutschsprachigen Schrifttums :

(GV). - Munchen, New York, London, Paris : Saur.

Bd. 1 - 6 bearb. unter d. Leitung von Peter Geils

u. Willi Gorzny.

ISBN 3-598-30000-X

$1700-1910 /$ bearb. unter d. Leitung von Hilmar

Schmuck u. Willi Gorzny. Bibliograph. u. red.

Beratung: Hans Popst u. Rainer Schöller

NE: Schmuck, Hilmar [Bearb.]

124. Schag - Schel. - 1984.

(C) 1984 by K. G. Saur Verlag KG, München

Techn. Realisierung und Druck: Norbert Gärtner, Mainz-Kastel

Binden: Karl Schaumann, Darmstadt

Printed in the Federal Republic of Germany

ISBN 3-598-30000-X (Gesamtwerk) 